\title{
Relief efforts of school material in the Great East Japan Earthquake - For documentation of repair immersed in seawater at Iwate Prefectural Takata High School -
}

\author{
SEN Suzuretsu, HIRAI Ayumi \\ Kanto Gakuin University, Meisei University \\ 3-22-1 Kamariya Minami, Kanazawa-ku, Yokohama-shi, Kanagawa 236-8502 \\ 2-1-1Hodokubo, Hino-shi, Tokyo 191-8506 \\ Japan \\ sen@kanto-gakuin.ac.jp , hiraia@ge.meisei-u.ac.jp
}

\begin{abstract}
Many of the Tohoku region of the school library were affected by the Great East Japan Earthquake. Takata high school at Iwate Prefecture in the Tohoku region cases that suffered catastrophic damage during the tsunami. Many of the school materials that were in the school library gets wet with seawater. It was carried out relief activities of such documents. Restoration method that using water washing and the flat drying is up to professional standard. However, it adopted a method to be able to easily perform at low cost and can perform a restoration by few exercises.
\end{abstract}

Keywords: School materials repair, Water cleaning, Earthquake, Tsunami

\section{Damage of Iwate prefecture of school libraries in the Great East Japan Earthquake}

Great East Japan Earthquake of magnitude 9.0 maximum seismic intensity 7 has occurred in the March 11, 2011. There were a large damage caused by the tsunami in the coastal part of the close to the epicenter. Iwate Prefecture was dead or missing has reached more than 6,800 people.

Japan School Library Association has carried out a survey of the school library. Schools need rebuilding in the disaster there were 10 schools, and no book available there were eight schools, and four school available but there was damaged.

\section{Launch of the Morioka university disaster area Library Support Project}


Morioka university, located in Iwate Prefecture, had been responsible for the training of the Tohoku region of librarians and school librarian. Therefore, Morioka university went to help taking advantage of the professional knowledge and skills to the affected areas of the school library.

However, initially it was not possible to even grasp needs such as "what school library is seeking assistance?" And, know-how was also a no groping of the state is referred to as "what kind of may be carried out to help?". So, it was decided to explore the support needs make a two policies. Cooperation explored with organizations that are doing the support activities in the affected areas libraries, and hearing in person directly to the affected areas of local governments and libraries.

\section{Kind of support activities}

Because damage situation in the affected areas of the library were different from each other, is an infinite variety also the contents of the support. However, it can be classified into three types roughly. First was a relief repair activities of library materials, second was a preparatory assistance activities aimed to the library of the resumption, and third was a continuation of support activities after the resumption. Support the needs of the library side began to change as the first from the third with the passage of time from the earthquake disaster.

Relief repair activities of library materials were carried out early after the earthquake. For example, digital archives which were carried out as media conversion, and repair activities of local materials and school materials etc. Preparatory assistance activities aimed to the library of the resumption were many in the time that has passed through about one to two years from the earthquake. For example, data input and equipment work of donated books, and bookshelf layout etc. Continuation of support activities after the resumption were carried out with the aim of increasing the number of students, which was less after the earthquake. For example, Shadow Theatre etc.

\section{Repair immersed in seawater at Iwate Prefectural Takata High School}

\subsection{Background}

At the time of the Great East Japan Earthquake, Prefectural Takada High School of Rikuzentakata was devastated surging tsunami up to the third floor school building. School building was torn down in October 2012 after a year and a half from the earthquake. Takada high school teacher and Morioka university library staff at the time of the demolition, found the school materials, such as students Journal-school newspaper that had barely left without shed on the third floor of the library. Pick up collected school material was a situation that has been 
covered with and a half sand and mold also left more than a year. Professor of psychology of Morioka university there was a margin that had been a consultation counsellor of Takada High School. So the Morioka university disaster area Library Support Project is to undertake the repair activity of the affected documents of Takata High School.

\subsection{The significance of the repair activities}

School materials created in the school such as school newspaper or Student newsletter or School document, unlike such general books and brochures, distribution range is very limited, the other alternatives do not exist can be said that many materials.

The school materials are intended as a living document to tell the school history. To restoration these school materials are not only encouraging the faculty and students of the reconstruction of the middle school, it can be to support the identity.

Not only professors and library staff of Morioka university in this time of repair activities, many students took part in as a volunteer. Takata high school affected by the disaster from Morioka are separated by $150 \mathrm{~km}$. Because it is not too much for transportation means is also earthquake, students for volunteer, could not quite go. By providing the opportunity of disaster relief activities in the University there is a great significance. Many of the students who participated as a student volunteer was the one who aims to curators or librarians or school librarians in the curator program course and librarian program course. Therefore, students have a good understanding about the significance to convey the cultural assets to the next generation. By experience actually repair activities taking advantage of the learned expertise in daily class, was more realize the expertise of the curator and librarian.

\subsection{The method of repair}

Repair material that has been requested from the Takada High School is 1,141 in total. (1)Mr. Tetsuzo Tanikawa autograph one sheet. (2)Books such as school guidance and research bulletin had 14. (3)Pamphlet, such as school handbook is 19. (4)Such as print and newspaper scrap 1107 sheets.

(1) is a sign paper that Mr. Tetsuzo Tanigawa of Hosei University President (1895 - 1989) was calligraphy that has been written Kenji Miyazawa poem "「まづもろともに から゙やく宇宙の 微塵となりて無方の空にちらばらう(Become a speck of shining together universe scattered until the empty End)」this sign paper was a symbolic presence of Takata High School, it was very valuable materials. The schoolyard was also stone monument that has been created based on this sign the paper, but it was swept away by the tsunami. Although there was a very 
valuable material water wet marks and mold had occurred. In our repair skills of the project it was impossible to repair. For this reason, we decided to carry out the repair ask the professional materials preservation and restoration. When the repair work was done in Tokyo. Members of the project was to accompany the repair work and indication of the repair. It will be described concrete repair work. First to perform the mold fungus test, to verify the possibility of breeding of mold. Next, remove the caked sand in the dry cleaning. Water washing, de-acidification, and was carried out flattening.

For school material from (2) to (4), also covers seawater any of the material, is a state in which the caked detailed silt. Seawater specific slime was also to the touch by hand. Mold has occurred in part of the school materials. Rust was also school materials that occurred from the clip portion. But our project decided to make the material repair in Morioka university by ourselves. Booklet materials, such as research bulletins was small wrinkles of water wet. For this reason, we decided to carry out the dry cleaning without dismantling. Not only the dry cleaning, we decided to repair conduct water washing and flattening drying. In our project, there was the experience of a dry cleaning repair.However, water cleaning and flattening drying was inexperienced. For repair method was adopted a document repair technology that Tokyo Document Rescue Party is doing in the affected areas. It invited the two staff members of Tono Cultural Research Center in Morioka university was carried out work while asked to the borrowing and technical guidance materials.

\section{Repair process}

Repair processes were conducted in the following manner. Numbering materials, Selection of materials, Water cleaning, Filing of materials.

\subsection{Numbering materials, Selection of materials}

Numbering by materials associate professor, library staff three people, one student gave a work. In order to prevent the mistake of lost or pagination of when performing a repair to each point we will continue to the numbering with a pencil in the left corner of the material. Materials that finished the numbering, was carried out to create a manifest by using the PC on the spot. In addition, we dry cleaning to the front of the water washing except for the roughly silt.

At the stage of the selection of the next school material, the school material to check one by one, we will continue to sorting whether material can withstand the water washing. Such as the material that has been written in such as water-based ink and water-based ballpoint pen disappear character and the water wash. Such a possible document sorted as material of dry 
cleaning only. Associate Professor one person, library staff three people was responsible for this process.

\subsection{Water cleaning}

Water cleaning work of materials were made to flow work, it requires a lot of manpower. As a result of recruiting student volunteers, students of 19 people curator program course and the librarian program course gave me to participate in the water cleaning work. There are also participants from outside except Morioka university who has two staff members of the Japan Library Association, Ayumi Hirai who is a co-authors and one student joined form Meisei university librarian course, and there has been a participant of Iwate Medical University librarians one person. Work of water cleaning took three days. There were 50 participants in a three day total. All three days gave a work by three hours in the morning and afternoon.

The first step of water cleaning was sprayed a mist containing the rubbing alcohol in order to keep the mold. School material that can be water cleaning is crowded sandwiched between the non-woven fabric and the net for the screen door so as not to damage. In a vat filled with water soaked the school materials sandwiched between non-woven fabric and the net. It dropped the dirt and salt and gently stroked with a brush.

It was repeated twice washed to drop firmly. Prepared two vat to drop firm, it was repeated twice with water cleaning. After the water washing, in order to remove firm moisture, and to absorb moisture in a large chamois towel to be used in swimming. After drained, and prepare it for drying sandwich with corrugated board and filter paper. Superimposed a sandwich has been corrugated board and filter paper and place a weight from above. And, it dried for two days while applying the wind a large fan. After the drying is complete, take out the school materials from the sandwich of filter paper and corrugated board. School material before water cleaning contains salt, gritty or wrinkle with sand was drunk. But, after the water washing is missing salt, and by dry, texture also becomes smooth, wrinkle was also gone. School materials became a state that can withstand the save again by a series of work. To classify each numbering to make it easier to filing the school materials. Repair work of the water cleaning is completed.

Part of the school materials was also what is difficult to wash from the point of view of form and state. Such is has undergone a carefully dry cleaning one by one use, such as a brush or animal hair of toothbrush or sponge.

\subsection{Filing of materials}


It was carried out one by one filing in a dedicated storage container for use in museums. This storage container were a made of paper, it was easy to respond to changes in humidity and temperature, it was resistant to long-term storage because it made of acid-free paper.

Followed the attachment order of when the newspaper scrap was also entrusted, was attached one by one point in the same order in the new scrapbook. Water cleaning was carried out in spring vacation, the filing even though carried out during the class period, but 37 students were participated in total. Thus repaired school materials was able to return to Takata High School.

\section{Looking back on the repair activities}

Even without applying an expensive cost, it was able to materials relief with familiar and inexpensive tool. Simple and low-cost restoration method are important. Because it is possible to repair if you collect even manpower. And it was rarely able to experience repair work, it should become students also a good experience.

Repair activities could be carried out smoothly, because of there were three factors. The first point is that was able to work with other agencies and organizations. Rather than support the project alone, be to support activities in conjunction with the aggressively other agencies and organizations, it made it possible to quickly support activities. Also while building a human connection through the activity, it was possible also to accumulate support know-how and skills.

The second point is, members not only professor with expertise in library and information science, is that was also participating university librarians and students.

Three parties could be involved in activities together. According to the situation, to coordinate the personnel that take advantage of the features of the three parties were able optimal activity. If expertise is required of library practice was primarily support the university librarians. If university professor who specializes in library and information science in the case of specialized knowledge necessary assistance was mainly support. If a large number of manpower required was able to mobilize the curator program course and librarian program course students. Each other of the conflict in accordance with the situation went very well.

The third point is that the physical distance was close. In the case of Takada High School was away 150 kilometers, But Morioka Compared to Tokyo and Sendai distance is much closer. It was capitalize the distance benefits that the same Iwate prefecture. We can be negotiated went immediately to the disaster area, was able to respond quickly.

Support is not the end When do something once. It continued support to community-based is important. Disaster not only to revive the school library to once again before the earthquake of 
the state, it must have the support as a target a school library that can better service than before the earthquake. Future challenges, dissemination of simple and low-cost repair methods, such as was carried out this time, and new proposals for the collection and preservation of the way of the school materials are also necessary.

\section{Biographical note}

Suzuretsu Sen works as Associate Professor at Kanto Gakuin University in Yokohama, Japan since 2014, belong to the development course of librarians and teacher librarians. When Great East Japan Earthquake happened years (2011) was a member of the Morioka University, that is located in Iwate that had a big damage in the Great East Japan Earthquake. For this reason, it have continued to restoration activities of public libraries and school libraries in Iwate region.

Ayumi Hirai works as Professor at Meisei University in Tokyo, Japan. Her main research is a library and information science, and development librarians and teacher librarians. She interest in the remedy of materials, it participated in the restoration activities in Takata high school. 